International Journal of Current Advanced Research

ISSN: O: 2319-6475, ISSN: P: 2319 - 6505, Impact Factor: SJIF: 5.995

Available Online at www.journalijcar.org

Volume 6; Issue 4; April 2017; Page No. 3054-3056

DOI: http://dx.doi.org/10.24327/ijcar.2017.3056.0179

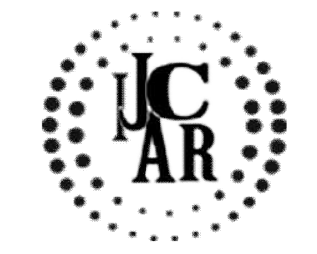

Research Article

\title{
AWARENESS OF RELATIONSHIP BETWEEN BALANCED DIET AND ALOPECIA IN STUDENTS COMMUNITY-AN QUESTIONNAIRE BASED STUDY
}

\author{
Nivetha .Gㅜ., Geetha R.V ${ }^{1}$ and VishnuPriya $V^{1}$
}

${ }^{1}$ Department of Microbiology, Saveetha Dental College, Chennai

2Department of Biochemistry, Saveetha Dental College, Chennai

\section{A R T I C L E I N F O}

Article History:

Received $18^{\text {th }}$ January, 2017

Received in revised form $19^{\text {th }}$ February, 2017

Accepted $22^{\text {nd }}$ March, 2017

Published online $28^{\text {th }}$ April, 2017

\section{Key words:}

Nutrition, balanced diet and alopecia.

\begin{abstract}
A B S T R A C T
Aim and Objective: To create the awareness of relationship between balanced diet and alopecia in students community.

Background: Balanced diet is a diet containing adequate energy and all the essential nutrients that cannot be synthesised in adequate quantities by the body. Balanced diet is adequate for growth, energy needs, nitrogen equilibrium, repair, and maintenance of normal health.Alopecia means hair loss from head or other parts of body which is due to nutrition deficiency or certain other factors.

Materials and Methods: A few questionnaires were circulated among the student of Saveetha dental college and got about 100 response. The questionnaire contains details regarding their balanced diet, their food habits and their knowledge about alopecia.

Results: Most of them are aware of balanced diet and how to maintain good healthy life.
\end{abstract}

Copyright $\bigcirc 2017$ Nivetha.G., Geetha R.V and VishnuPriya V. This is an open access article distributed under the Creative Commons Attribution License, which permits unrestricted use, distribution, and reproduction in any medium, provided the original work is properly cited.

\section{INTRODUCTION}

A balanced diet is not a crash diet, it is a way of eating all of the right nutrients that our body needs in order to be healthy. Everyone's bodies are different and often individuals require a different amount and type of nutrients. This can depend on age, gender, illness and the rate at which your body work.A balanced is one that helps to maintain or improve overall health. A healthy diet provides the body with essential nutrition: fluid, adequate essential amino acids from protein, essential fatty acids, vitamins, minerals, and adequate calories.[4] A balanced diet is one that gives our body the nutrients it needs to function correctly. In order to get the proper nutrition from your diet, you should obtain the majority of your daily calories from:fresh fruits, fresh vegetables, whole grain, legumes, nuts, and lean proteins[5]. It is more important because our organs and tissues need proper nutrition to work effectively. Without good nutrition, your body is more prone to disease, infection, fatigue, and poor performance [1]. Children with a poor diet run the risk of growth and developmental problems and poor academic performance. Bad eating habits can persist for the rest of their lives.At the core of a balanced diet are foods that are low in unnecessary fats and sugars but high in vitamins, minerals, and other nutrients.[2]. Alopecia, also known as hair loss or baldness, refers to a loss ofhair from part of the head or body.

*Corresponding author: Nivetha .G

Department of Microbiology, Saveetha Dental College, Chennai
The severity of hair loss can vary from a small area to the entire body.Typically inflammation or scarring is not present.Hair loss in some people causes psychological distress.Common types include: male-pattern hair loss, female-pattern hair loss, alopecia areata, and a thinning of hair known as telogen effluvium[3]. The cause of male-pattern hair loss is a combination of genetics and male hormones, the cause of female pattern hair loss is unclear, the cause of alopecia areata is autoimmune, and the cause of is telogen effluvium is typically a physically or psychologically stressful event. Telogen effluvium is very common following pregnancy.[4] Alopecia areata is not contagious.It occurs more frequently in people who have affected family members, suggesting heredity may be a factor.[6] Symptoms of hair loss include hair loss in patches usually in circular patterns, dandruff, skin lesions, and scarring. Alopecia areata (mild medium level) usually shows in unusual hair loss areas e.g. eyebrows, backside of the head or above the ears where usually the male pattern baldness does not affect. [7] In malepattern hair loss, loss and thinning begin at the temples and the crown and either thins out or falls out. Female-pattern hair loss occurs at the frontal and parietal.[8] There are several different types of foods that can help alleviate or control alopecia to some extent.some of the most commonly recommended alopecia areata foods are Foods that are high in calcium, such as tofu, soy products, nuts, nut milks, soymilk and certain leafy greens and omega 3 fatty acids, fresh fruits and vegetables etc.[9-10]. 


\section{MATERIALS AND METHODS}

A few questionnaires were circulated among the student of Saveetha dental college and got about 100 response. The questionnaire contains details regarding their balanced diet, their food habits and their knowledge about alopecia.

1) Do u have a proper balanced diet?
A) Yes
B) No
C) Don't know

2) What is more important meal for you in a day?
A) Breakfast
B) Lunch
C) Dinner

3) Are you satisfied with your existing eating habits?
A) Very satisfied
B) Satisfied
C) Not satisfied

4) What type of food do you prefer?
A) Organic food
B) Veggie
C) Balanced diet

5) Do you have any nutrition deficiency?
A) Yes
B) $\mathrm{No}$
C) Don't know

6) Do your diet rich in green leafy vegetables?
A) Yes
B) No
C) Sometimes

7) Do your diet rich in dry fruits?
A)Yes
B)No
C) Sometimes

8) Are you a vegetarian or non vegetarian
A) Vegetarian
B) Non vegetarian

9) If non vegetarian, how often do you take non veg?
A) Daily
B) Once in a week
C) Morethan once in a week

10) Do you have an habit of taking junk food inbetween meals?
A) Yes
B ) No
C) Sometimes

11) Do you consume tea or coffee everyday?
A) Yes
B) No
C) Sometimes

12) If yes, how many times in a day?
A) Twice a day
B) more than twice a day

13) Do your diet rich in high lipid content food?
A) Yes
B) No
C) Sometimes

14) Are you aware of alopecia?
A) Yes
B) No
C) Don't know

15) How many strands of hair do you loss per day approximately?
A) $0-50$
B) $50-100$
C) More than 100

16) Do you think malnutrition is major cause for hairfall?
A) Yes
B) No
C) Don't know

17) Are you undergoing any hairfalltreatment?
A) Yes
B) No

18) Is your irregular diet habits is a reason for hair loss?
A) Yes
B) No

\section{RESULTS}

An overall response rate of $100 \%$ was achieved as all students responded properly.The diagrams below explain their awareness on relationships between balanced diet and alopecia.

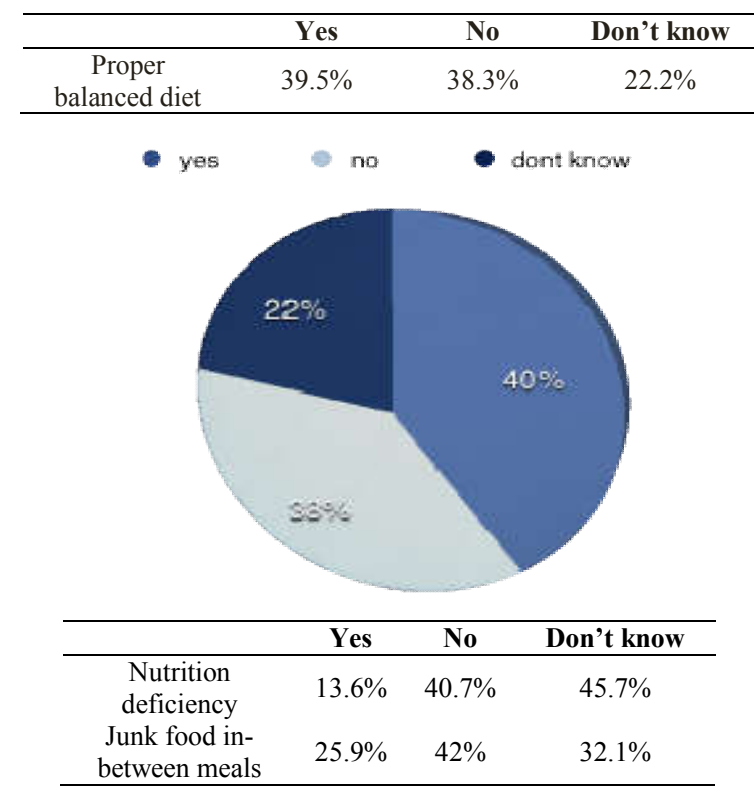

- nutrition deficiency ank food in-between meals

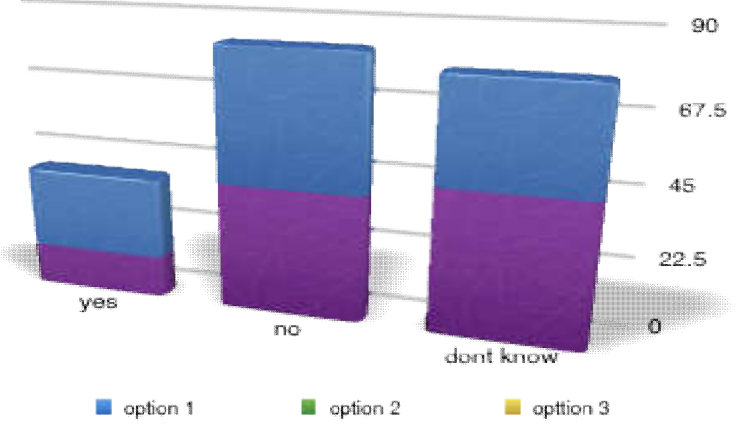

120

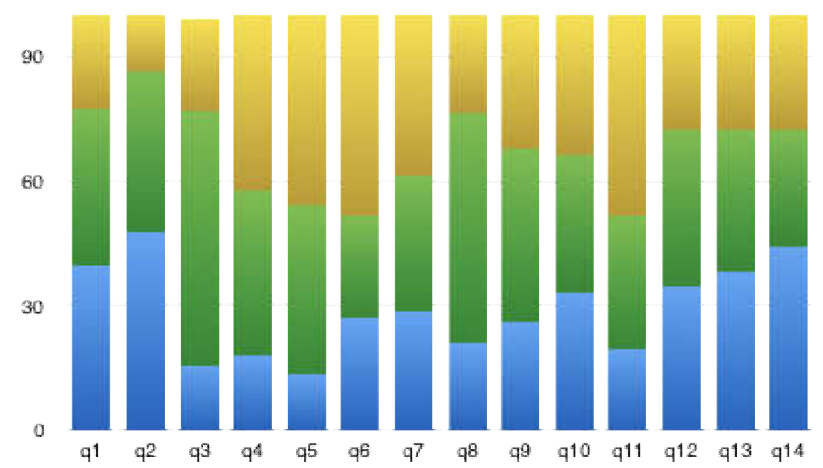

Overall relationship between balanced diet and 


\section{DISCUSSION}

From the above study it was concluded that $40 \%$ of students have their proper balanced diet. $48.8 \%$ of them stated that the most important meal of the day was considered to be breakfast. $62.5 \%$ of them were satisfied with their day to day habits. $41.3 \%$ of them prefer a balanced diet. $46.3 \%$ of them were unaware if they have any nutritional deficiencies. $48.8 \%$ of the respondents have a diet rich in green leafy vegetables. $37.5 \%$ add dry fruits to their diet. Of the total respondents, $81.1 \%$ were non vegetarians. $42.5 \%$ don't have the habit of taking junk food between meals. $33.8 \%$ consumed coffee or tea daily. $35 \%$ of them were unaware of what is alopecia. $45 \%$ felt that malnutrition is the major cause of hair fall and $57.7 \%$ felt that their food habits were responsible for that.

\section{CONCLUSION}

Thus the study reveals the relationship between balanced diet and alopecia among dental students. Most of them were aware of balanced diet and how to maintain a good healthy diet. They also knew about treatment, cause and effects of alopecia.

\section{References}

1. Sargent RG, Thompson SH, Richter D, Corwin SJ \& Rogan TJ (2000): A study of body weight concerns and weight control practices of 4 th and 7 th grade adolescents. Ethn. Health 5, 79
2. Hunt N, McHale S. The psychological impact of alopecia. Br Med Jour 2005;331:951

3. Selected Disorders of Skin Appendages--Acne, Alopecia, Hyperhidrosis.". The Medical clinics of North America. $99 \quad$ (6): 1195-211. doi:10.1016/j.mcna.2015.07.003. PMID 26476248.

4. Fitzgerald M (2014). Diet Cults: The Surprising Fallacy at the Core of Nutrition Fads and a Guide to Healthy Eating for the Rest of US. Pegasus Books. ISBN 978-1-60598-560-2.

5. Nestle, Marion (2006). What to Eat. New York: North Point Press (Farrar, Straus and Giroux). p. 611. ISBN 978-0-86547-738-4.

6. Zoe Diana Draelos (August 30, 2007), Alopecia Areata. MedicineNet.com. Retrieved on December 2, 2007

7. Alaiti, Samer. "Hair growth". e Medicine. Archived from the original on January 21, 2015.

8. ^ Bergler-Czop, B; Brzezińska-Wcisło, L (2004). "Hormonal factors in etiology of common acne". Polskimerkuriuszlekarski: organ PolskiegoTowarzystwaLekarskiego. 16 (95): $\quad$ 4902. PMID 15518435 .

9. Nalluri, R; Harries, M (February 2016). "Alopecia in general medicine.". Clinical medicine (London, England). 16 (1): 74-8. doi:10.7861/clinmedicine.161-74. PMID 26833522.

10. Alaiti, Samer. "Hair growth". eMedicine. Archived from the original on January 21, 2015.

\section{How to cite this article:}

Nivetha .G et al (2017) ' Awareness of Relationship Between Balanced Diet And Alopecia In Students Community-An Questionnaire based Study', International Journal of Current Advanced Research, 06(04), pp. 3054-3056.

DOI: http://dx.doi.org/10.24327/ijcar.2017.3056.0179 